\title{
O ENSINO DA ARGUMENTAÇÃO NOS PROCESSOS DE LEITURA E DE ANÁLISE LINGUÍSTICA NA EDUCAÇÃO BÁSICA
}

\section{TEACHING ARGUMENTATION IN READING AND LINGUISTIC ANALYSIS PROCESSES AT BASIC EDUCATION}

ERIVALDO PEREIRA Do NASCIMENTO*

RESUMO: Neste artigo, refletimos sobre o ensino do fenômeno da argumentação na Educação Básica, com o objetivo de demonstrar como trabalhar a argumentatividade nos processos de leitura e de análise linguística, a partir de uma concepção linguístico-discursiva desse fenômeno da linguagem humana. Trata-se, portanto, de um trabalho reflexivo e propositivo, fundamentado em duas correntes teóricas: A Teoria da Argumentação no Discurso, proposta por Perelman (1999), e a Teoria da Argumentação na Língua, de Ducrot e seus colaboradores $(1987,1988,1994)$. Neste trabalho, de maneira mais específica, mostraremos como, a partir de alguns gêneros textuais, é possível trabalhar habilidades e estratégias argumentativas, na sala de aula, considerando, entre outras

* Docente da UFPB - Universidade Federal da Paraíba. E-mail: erypn@hotmail.com. 
coisas, as estratégias argumentativas retóricas e linguísticas mais frequentes no gênero e a relação entre conteúdo e argumentatividade. Mostraremos, ainda, atividades de análise linguística em que se observa o funcionamento de determinadas estratégias argumentativas presentes na estrutura da língua.

PALAVRAS-CHAVE: Argumentação. Ensino. Gêneros Discursivos. Análise Linguística.

ABSTRACT: In this paper, we discuss the matter of teaching argumentation phenomenon at basic education, aiming to demonstrate how to teach argumentation in reading and linguistic analysis processes, based on a discursive and linguistic conception of this phenomenon of the human language. Therefore, it is a reflexive and propositional work based on two theoretical currents: The Discourse Argumentation Theory, proposed by Perelman (1999), and the Theory of Argumentation in the Language-System, by Ducrot and his collaborators $(1987,1988,1994)$. In this paper, we will show more specifically how it is possible to work argumentative abilities and strategies, at different discourse genres, in the classroom, taking into consideration, among other things, both rhetorical and linguistic argumentative strategies that are more frequent in a specific genre and the relationship between content and argumentation. Finally, we will show some activities of linguistic analysis, which the functioning of determined argumentation strategies is observable in the linguistic system.

KEYWORDS: Argumentation. Teaching. Discursive Genres. Linguistic Analysis 
Neste artigo, propomos uma reflexão sobre o ensino do fenômeno linguístico-discursivo da argumentação na Educação Básica ${ }^{1}$, com o objetivo de demonstrar como trabalhar a argumentatividade nos processos de leitura e de análise linguística, pautados em uma visão de ensino de língua voltado para o desenvolvimento da competência ${ }^{2}$ comunicativa ou linguístico-discursiva.

Fundamentamos nossa proposta a partir de duas correntes teóricas que pensam o fenômeno da argumentação humana: A Teoria da Argumentação no Discurso, proposta por Perelman (1999), e a Teoria da Argumentação na Língua, de Ducrot e seus colaboradores $(1987,1988,1994)$.

A primeira corrente, da Retórica, explica como os fatos, valores, crenças e outros objetos de acordo são utilizados argumentativamente, no momento em que interagimos. A proposta por Ducrot, na Semântica Argumentativa, verifica como a argumentatividade já está presente na própria estrutura da língua.

Propomos que é possível utilizar essas correntes teóricas de maneira complementar, quando estamos verificando o fenômeno da argumentação em diferentes gêneros textuais ou

1 Uma primeira versão deste trabalho foi apresentada no I ENPEB (Encontro de Professores da Educação Básica), realizado em 13 e 14 de dezembro de 2012, em Mamanguape-PB.

2 A partir da concepção de competência comunicativa proposta por Hymes (2000), que inclui não só o conhecimento a respeito do sistema de um idioma, mas também a capacidade de usá-lo, nós acreditamos que um dos objetivos do ensino de língua materna, na escola, é desenvolver no educando não só o conhecimento sobre a estrutura e o funcionamento da língua, mas, principalmente, a competência de usá-la de maneira eficaz em diferentes situações interativas; o que implica, entre outras coisas, a capacidade de refletir sobre o uso da linguagem e a capacidade de usar (ler e produzir) diferentes gêneros discursivos. 
discursivos ${ }^{3}$, principalmente na perspectiva do ensino. Além disso, elas nos fornecem ferramentas para refletir sobre a maneira como esse fenômeno tem sido trabalhado na sala de aula.

Essa reflexão se faz necessária, já que é comum encontrarmos equívocos, sobretudo nos livros didáticos, a respeito do ensino da argumentatividade e que, de certa maneira, isso acaba influenciando no processo de ensino-aprendizagem desse fenômeno linguístico.

0 primeiro equívoco diz respeito à inclusão da argumentação como um conteúdo específico, distante dos outros conteúdos relativos ao ensino de língua. É comum dedicar-se um capítulo específico para o ensino de técnicas argumentativas. O segundo equívoco, correlacionado com o anterior, é que há gêneros argumentativos e gêneros não argumentativos (NASCIMENTO, 2012a, p. 70).

A argumentação é inerente à linguagem humana (DUCROT, 1988) e isso ocorre porque sempre que interagimos temos intenções e essas intenções se materializam nos enunciados que produzimos (NASCIMENTO, 2012c). Consequentemente, todos os gêneros, em maior ou menor grau, são argumentativos.

Obviamente há gêneros em que a argumentatividade é mais explícita e salta aos olhos, em razão de sua função social: é o caso do artigo de opinião e da charge. Em outros, a argumentatividade é mais sutil e perpassa outras estratégias discursivas, é o caso de alguns gêneros literários, como o poema (NASCIMENTO, 2012a, p. 70).

3 Adotamos, neste trabalho, a concepção de gêneros discursivos de Bakhtin (2000 [1992]), que os considera como tipos relativamente estáveis de enunciados (textos) que são constituídos histórica e socialmente. Assinalamos, no entanto, que trataremos os termos gêneros textuais, gêneros do discurso e gêneros discursivos um pelo outro, indistintamente, para referir-se aos gêneros de textos, uma vez que não é nosso objetivo discutir questões teóricas a esse respeito. 
Por essa razão, um ensino de argumentação que exclua uns gêneros e promova outros já não se justifica mais. Da mesma forma, não nos parece pertinente trabalhar a argumentatividade como um conteúdo específico de língua, uma vez que ela permeia toda a linguagem humana.

Reiteramos que um ensino de língua que considere o real funcionamento da argumentatividade não a isolará como um conteúdo específico, mas a abordará em todas as fases do processo de ensino-aprendizagem: no ensino da leitura, da escrita e da análise linguística.

Uma leitura eficaz é aquela que, entre outras características, perscruta as intenções de quem produziu o texto e, para que isso ocorra, é necessário considerar as estratégias argumentativas utilizadas pelo locutor do texto. Da mesma maneira, um texto bem produzido é, entre outras coisas, aquele que consegue estabelecer um diálogo com seu interlocutor e explicita, na medida do possível e guardadas as características de cada contexto e gênero escolhido, as intenções de quem o produz. Assim, é impossível dissociar o ensino da escrita do ensino da argumentação. Semelhantemente, o ensino da análise linguística, ou seja, das estruturas da língua e do seu funcionamento, perpassa pela argumentação porque, como assinala Ducrot (1988), a argumentatividade já está inscrita na própria estrutura da língua (NASCIMENTO, 2012a, p. 71).

Consideramos que o processo de aprendizagem das estratégias argumentativas, por parte dos aprendizes de uma língua, será mais eficaz se trabalhado na sua correlação com o processo de leitura, escrita ou com a análise linguística. Por essa razão propomos que o ensino de argumentação faça parte de todo o conteúdo programático das disciplinas de língua e linguagem, associado à aprendizagem das habilidades de leitura e de produção textual, além da reflexão sobre o funcio- 
namento e o uso das estruturas linguístico-discursivas.

Reiteramos que a percepção das estratégias argumentativas presentes em um gênero textual é muito importante, se quisermos trabalhar com a leitura ou a produção desse gênero (NASCIMENTO, 2012a; 2012c). Naturalmente, o usuário que consegue enxergar como se dá o movimento argumentativo de um gênero e como um falante o utiliza, de acordo com as suas intenções, conseguirá, com mais facilidade, utilizar esse gênero de maneira mais eficaz, sob o ponto de vista interacional.

0 processo de ensino-aprendizagem da argumentação, em diferentes gêneros, passa naturalmente pela necessidade de compreensão desse fenômeno em cada um, de maneira específica, até mesmo porque é a partir de nossas intenções, do que desejamos para com o nosso interlocutor, que selecionamos um ou outro gênero de texto.

Neste artigo, de maneira mais específica, mostraremos como, a partir de alguns gêneros textuais, é possível trabalhar habilidades e estratégias argumentativas, na sala de aula, considerando, entre outras coisas, as estratégias argumentativas retóricas e linguísticas mais frequentes no gênero e a relação entre conteúdo e argumentatividade. Mostraremos, ainda, atividades de análise linguística em que se observa o funcionamento de determinadas estratégias argumentativas presentes na estrutura da língua.

Assinalamos, ainda, que este trabalho resulta de investigações teóricas e aplicadas que vêm sendo realizadas nos projetos Estudos Semântico-Argumentativos de Gêneros do Discurso (ESAGD) e Ensino de Leitura e de Produção de Gêneros do Discurso: perspectiva semântico-discursiva, a partir de Sequências Didáticas (ELPGD), no Laboratório Semântico-Pragmático de Textos (LASPRAT) e no Laboratório de Estu- 
dos Linguísticos (LAEL), ambos da UFPB. Essas investigações têm demonstrado, entre outras coisas, que o uso das estratégias argumentativas pode variar de um gênero para outro e determinados gêneros são mais propícios para determinadas estratégias argumentativas do que outros, em razão de suas funções sociointeracionistas.

\section{Os princípios da argumentação na Retórica}

A argumentação, enquanto fenômeno da linguagem humana, tem sido objeto de estudo desde os clássicos. Aristóteles, segundo Perelman (1999, p. 21), foi o primeiro a deter-se a essa problemática.

Aristóteles distinguiu, no seu Organon, duas espécies de raciocínios: os raciocínios analíticos e os raciocínios dialécticos. 0 estudo que daqueles empreendeu nos Primeiros e nos Segundos Analíticos valeu-lhe ser considerado, na história da filosofia, como o pai da lógica formal. Mas os lógicos modernos esqueceram, porque não lhes tinham percebido a importância, que ele tinha estudado os raciocínios dialécticos nos Tópicos, na Retórica e nas Refutações sofísticas, o que faz dele, igualmente o pai da teoria da argumentação (grifos do autor).

Ainda de acordo com Perelman, nos Analíticos, Aristóteles estuda formas de inferência válida, especialmente o silogismo. Pelo silogismo, é possível inferir uma conclusão de forma necessária, a partir de determinadas hipóteses. Para tal, foi desenvolvida a seguinte fórmula: "se todos os A são B e se todos os B são C, daí necessariamente que todos os A são C." (PERELMAN, 1999, p. 21)

A inferência é válida seja qual for a verdade ou a falsida- 
de das premissas, mas a conclusão só é verdadeira se as premissas forem verdadeiras. 0 exemplo clássico abaixo descrito (exemplo 1) demonstra um caso de uma conclusão verdadeira, uma vez que as duas premissas também são verdadeiras.

\section{Exemplo 1}

Premissa 1 - Todo homem é mortal.

Premissa 2 - Pedro é homem.

Conclusão - Logo, Pedro é mortal.

Aristóteles determinou ainda que a dialética interessa-se pelos argumentos utilizados numa controvérsia ou numa discussão com um único interlocutor, enquanto que a retórica diz respeito às técnicas do orador dirigindo-se a uma multidão reunida na praça pública, que não possui nenhum saber especializado ou é incapaz de seguir um raciocínio um pouco mais elaborado. No entanto, reconhece que em ambas as situações o objetivo é a defesa de uma tese: "Todos os homens participam, até certo ponto, de uma e de outra; todos se empenham dentro de certos limites em submeter a exame ou defender uma tese, em apresentar uma defesa ou uma acusação" (ARISTÓTELES, s/d, p. 29).

Ainda, segundo Perelman, a Retórica Moderna, do século XIX, relacionou a lógica aos raciocínios analíticos, negligenciando os raciocínios dialéticos.

Mas a nova retórica, em oposição à antiga, diz respeito aos discursos dirigidos a todas as espécies de auditórios, trate-se de uma turba reunida na praça pública ou duma reunião de especialistas, quer nos dirijamos a um único indivíduo ou a toda a humanidade; ela examinará inclusivamente os argumentos que dirigimos a nós mesmos, aquando duma deliberação íntima. (PERELMAN, 1999, p. 24, grifo do autor). 
Para esse estudioso, o objetivo da argumentação não é deduzir consequências de certas premissas, mas provocar ou aumentar a adesão de um determinado auditório às teses que um orador apresenta, o que pressupõe um contato entre um orador e seu auditório (interlocutores), mesmo que se trate de uma deliberação íntima. Ainda acrescenta que a sociedade reconhece a importância desses contatos, procura organizá-los e torná-los obrigatórios: "Vimos que toda a argumentação pressupõe o contato entre os espíritos, que as instituições sociais e políticas podem favorecer ou impedir" (PERELMAN, 1999, p.31).

O autor ainda acrescenta que a argumentação não tem unicamente como finalidade a adesão puramente intelectual de um auditório, ela pode visar à ação, ou pelo menos criar uma disposição para a ação. 0 auditório, por sua vez, não é constituído necessariamente por aqueles aos quais o orador se dirige expressamente, mas é concebido por Perelman (1999, p. 33) como "o conjunto daqueles que o orador quer influenciar pela sua argumentação”. Esse conjunto é muito variável, segundo o próprio autor, e pode ir desde o próprio orador (numa deliberação íntima) até à humanidade inteira, "ou, pelo menos aos membros que são competentes e razoáveis e que eu qualifico como auditório universal, passando por uma variedade infinita de auditórios particulares" (PERELMAN, 1999, p. 34).

0 referido filósofo diz que o orador deve preocupar-se com a adesão às premissas, para que o auditório, aceitando-as, aceite também a conclusão. Logo, a finalidade da argumentação não é provar a verdade da conclusão a partir da verdade das premissas, mas transferir para a conclusão a adesão concedida às premissas. 0 orador deve adaptar-se ao auditório, escolhendo como premissas de sua argumentação 
teses admitidas pelo auditório. Além disso, acrescenta que seria ridículo o orador não se preocupar com as reações do seu interlocutor, "que é levado, necessariamente, a passar do papel de auditório passivo a uma participação ativa no debate" (PERELMAN, 1999, p. 35).

A argumentação, para Perelman (1999, p. 48), "se insere num pensamento cujos diversos elementos são solidários uns dos outros". Cabe, portanto, ao orador, proceder a uma escolha desses elementos (fatos e valores, forma e linguagem), manifestando uma tomada de posição.

Escolha de elementos, escolha de um modo de descrição e apresentação, juízo de valor ou de importância, todos esses elementos são considerados tanto mais justificadamente como manifestando uma tomada de posição, quando mais nitidamente se veja que outra escolha, outra apresentação, outro juízo de valor se lhes poderia opor (PERELMAN, 1999, p. 54).

Assim, os estudos retóricos preocupam-se em descrever quais as estratégias argumentativas que um orador deve escolher para fundamentar sua interação, ou seja, que fatos, exemplos, valores, presunções, crenças e outros elementos devem ser utilizados e de que maneira, para que se obtenha a adesão de um auditório ao que se lhe é apresentado.

0 autor ainda acrescenta que a escolha de certos elementos, quando sustentados e apresentados em um discurso, "trá-los para o primeiro plano da consciência, dando-lhes, com isso, uma presença que impede negligenciá-los" (1999, p. 55). Para ele, a presença atua de maneira direta sobre a nossa sensibilidade, mas também pode oferecer inconvenientes, pois da mesma maneira que distrai os auditores (interlocutores) pode conduzi-los numa direção não desejada pelo ora- 
dor (locutor): "É por isso que os conselhos de certos mestres da retórica, que preconizam a necessidade de se recorrer a realidades corporais para comover o auditório, nem sempre devem ser seguidos" (PERELMAN, 1999, p. 55).

Perelman (1999, p. 61) também assinala a importância da linguagem na argumentação: "Num discurso, todos os elementos de que o orador fala só podem ser descritos através de uma linguagem e esta deve ser compreendida pelo auditório. Por isso, os factos evocados comportam, para além do que é dado, a maneira de os interpretar e descrever".

Ele afirma que um fenômeno pode ser descrito de duas maneiras: isolando-o do contexto, ou não. Isolando o fenômeno do contexto, podem ser observadas relações de causa e efeito, meio ou fim, "um símbolo de um conjunto mais vasto, um primeiro passo numa direcção" (1999, p. 61). No entanto, reconhece que a interpretação não é somente seleção e, por esse motivo, "ela pode ser criação de significação, inserção num contexto novo, numa teoria original" (PERELMAN, 1999, p. 62). Desta maneira, o estudioso admite a importância do contexto na interpretação, e, consequentemente, da confrontação de pontos de vista para o estabelecimento do sentido de um texto: "Vê-se nitidamente o quanto a clareza de um texto é uma propriedade relativa aos intérpretes: pode ser constatada no seguimento da confrontação de pontos de vistas, mas não considerada como uma qualidade prévia a esta confrontação" (PERELMAN, 1999, p. 62).

Para Perelman (1999), a multiplicidade de interpretações é resultado de controvérsias e divergências de pontos de vista a respeito de um texto e essa multiplicidade é responsável pelo estabelecimento do sentido do texto: "Um sentido parece dado quando o texto se afigura claro, isto é, quando se vê apenas uma interpretação razoável. Mas o que parece uma 
qualidade do texto pode resultar da ignorância ou da falta de imaginação" (PERELMAN, 1999, p. 62).

0 autor ainda acrescenta que, ao contrário das linguagens artificiais, como a matemática, que tentam eliminar a ambiguidade, as línguas naturais são propícias à ambiguidade, logo às múltiplas interpretações: "Nas línguas naturais, com efeito, a ambiguidade, a possibilidade de múltiplas interpretações, seria a regra" (PERELMAN, 1999, p. 63).

Por conta dessa ambiguidade comum às línguas naturais, recomenda Perelman (1999) que, para garantir uma compreensão da mensagem, sem falhas, se procure no contexto, no orador e no auditório, suplementos para eliminar a ambiguidade e os mal-entendidos.

Uma vez que os termos por si só não podem já garantir uma compreensão sem falhas da mensagem, é preciso procurar fora do termo, na frase, no contexto, verbal ou não, no que se sabe do orador e do seu auditório, suplementos de informação que permitam reduzir o mal-entendido, compreender a mensagem de acordo com a vontade daquele que a emite (PERELMAN, 1999, p.64).

Finalmente, Perelman (1999, p. 65) posiciona-se a respeito dos elementos linguísticos e os seus efeitos na mensagem. Diz ele que o uso normal da linguagem oferece múltiplas possibilidades de escolha - "o jogo das qualificações, das categorias gramaticais, das modalidades na expressão do pensamento, das ligações estabelecidas entre as proposições" - e isso "permite hierarquizar os elementos do discurso, pôr o acento neste ou naquele dos seus aspectos".

Convém assinalar que o autor não se detém em um estudo mais sistemático dos elementos linguísticos e sua relação com a argumentatividade. No entanto se percebe que Perel- 
man (1999) aponta para o fato de que esses elementos têm função argumentativa no discurso. 0 filósofo também considera a existência do auditório (receptores) como elemento indispensável para a determinação do conceito de argumentação. Desta maneira, o seu estudo, na nossa perspectiva, se soma aos de alguns teóricos da Teoria da Argumentação, dos quais trataremos mais adiante.

\section{Os princípios da argumentação na língua}

A Teoria da Argumentação na Língua (TAL), proposta por Ducrot e colaboradores, parte da premissa de que a argumentação está marcada na própria língua, desta maneira se opõe à concepção descrita anteriormente. Para Ducrot (1988), a conclusão não se explica somente por meio do fato utilizado como argumento, mas principalmente através da forma linguística utilizada pelo locutor na apresentação desse fato.

A argumentação, na perspectiva aqui adotada, deixa de ser vista como uma simples habilidade para convencer e persuadir, utilizada, principalmente, em determinados textos escritos e falados, e passa a ser compreendida como uma característica intrínseca à linguagem (para Ducrot, 1988) e à interação humana (para Nascimento, 2012a; 2012c), consequentemente, que permite que o falante, ao utilizar a língua, imprima suas intenções e sua subjetividade.

A afirmação de que a própria estrutura da língua já possui marcas argumentativas justifica-se pelo fato de que, de acordo com as intenções que possui o falante, ele seleciona determinadas estruturas linguísticas, uma vez que estas, e não outras, são úteis para o que ele pretende dizer ou fazer. 
Além disso, convém acrescentar que, nas escolhas realizadas, dentro das possibilidades que a língua lhe oferece, fica impresso o ponto de vista do falante sobre o objeto de sua interação. Portanto, é dessa maneira que a argumentação vai da estrutura da língua para o seu uso.

Ducrot (1988) afirma que o objetivo geral de sua teoria da argumentação é opor-se à concepção tradicional do sentido. Ele relata que, geralmente, se distinguem três indicações no sentido do enunciado: objetivas, subjetivas e intersubjetivas. As indicações objetivas consistem na representação da realidade, as subjetivas indicam a atitude do locutor frente à realidade e as intersubjetivas dizem respeito às relações do locutor com as pessoas a quem se dirige.

Como exemplo dessa descrição, Ducrot (1988, p. 50) traz o seguinte enunciado.

\section{Exemplo 2}

Pedro é inteligente (Pedro es inteligente)

No exemplo acima, o aspecto objetivo do enunciado é a descrição de Pedro, o subjetivo indica uma espécie de admiração do locutor por Pedro e o aspecto intersubjetivo ocorre porque o enunciado permite ao locutor pedir ao seu destinatário que confie em Pedro, por exemplo. Ducrot ainda acrescenta que o aspecto objetivo é chamado frequentemente de denotação e os aspectos subjetivo e intersubjetivo, de conotação.

Ducrot (1988, p. 50), contrapondo-se à concepção tradicional de sentido, apresenta sua teoria. Para esse linguista, a linguagem ordinária não possui uma parte objetiva, uma vez que os enunciados não descrevem diretamente a realidade: "Não acredito que a linguagem ordinária possua uma parte objetiva, tampouco que os enunciados da 
linguagem acessem diretamente a realidade; ou seja, não a descrevem diretamente ${ }^{4 "}$ (DUCROT, 1988, p. 50, tradução nossa). Para o autor, se a linguagem ordinária descreve a realidade, é por meio dos aspectos subjetivo e intersubjetivo que o teórico os reúne, denominando-os de valor argumentativo dos enunciados.

Retomando o exemplo 2 (Pedro é inteligente), Ducrot (1988) afirma que a descrição de Pedro está muito ligada à admiração subjetiva que Pedro desperta no locutor, e acrescenta que, ao dizer esse enunciado, o locutor pede ao seu interlocutor que se porte de com Pedro.

Para Ducrot, portanto, a língua é fundamentalmente argumentativa. Essa tese recebe ainda um adendo, realizado por Espíndola, para afirmar que não só a língua é argumentativa como também o seu uso.

Filiamo-nos à tese de Anscombre-Ducrot para quem a língua é fundamentalmente argumentativa, fazendo um adendo a essa tese: o uso também é argumentativo. Dessa forma reescrevemos a tese original de Asncombre e Ducrot - a língua e o seu uso são fundamentalmente argumentativos (ESPÍNDOLA, 2003, p.1).

Convém acrescentar aqui que a preocupação de Ducrot é com a estrutura e não com o uso dessa estrutura, muito embora acabe por fazer referência, em muitos dos seus conceitos, aos contextos intra e extralinguístico, ou seja, ao uso da língua. Isso ocorre, por exemplo, quando determina o valor argumentativo de uma palavra: Para Ducrot, o valor argumentativo de uma palavra é definido pela orientação que esta pa-

4 "No creo que el lenguaje ordinario posea una parte objetiva ni tampoco creo que los enunciados del lenguaje den acceso director a la realidad; en todo caso no la describen directamente" (DUCROT, 1988, p. 50). 
lavra dá ao discurso.

Assim, no exemplo 1, de acordo com Ducrot, não seria possível continuar o discurso afirmando ...logo não poderá resolver esse problema (luego no podrá resolver ese problema). Segundo o autor, a construção possível seria Pedro é inteligente, logo poderá resolver esse problema (Pedro es inteligente, luego podrá resolver ese problema). Se o locutor pensa que Pedro é incapaz de resolver determinado problema, ele teria de utilizar a palavra mas (pero), no lugar da palavra logo (luego). Isso demonstra como uma palavra funciona argumentativamente no discurso.

A palavra sentido, em Ducrot (1988, p. 52), significa, ao mesmo tempo, significação e direção: "A palavra sentido significa pelo menos duas coisas. Por uma parte significação e por outra, direção, em inglês meaning e direction respectivamente". Ele acrescenta que essa polissemia da palavra sentido, própria das línguas românicas, é muito significativa, pois indica que o sentido de uma palavra é, ao mesmo tempo, uma orientação no discurso: essa é a ideia que ele pretende expressar com a noção de valor argumentativo. Desta maneira, pode-se perceber que, para Ducrot (1988), a argumentação está ligada não somente ao sentido estrito do enunciado, mas à direção que esse enunciado dá ao discurso.

Assim, a utilização de uma palavra, termo ou estrutura linguística, em um enunciado ${ }^{5}$, permitiria determinadas direções (continuidades discursivas), em detrimento de outras, provocando determinados efeitos de sentido. Por essa razão,

5 Vale ressaltar que o conceito de frase e enunciado não se confundem nessa teoria. A frase é vista como uma entidade linguística abstrata, que não pertence ao campo do observável. É essa construção abstrata que permite a realização do enunciado. Este é observável, é a manifestação da frase, logo um fragmento do discurso. A língua, por sua vez, é composta de uma sucessão de frases; enquanto o discurso é composto por uma sucessão de enunciados. 
podemos afirmar que argumentação e sentido, nesta teoria, estão estritamente relacionados.

Para estabelecer o sentido de um enunciado e, consequentemente, do discurso, Ducrot cria uma regra: supondo que um discurso tenha dois segmentos sucessivos, do tipo S1 + S2, se o segmento S1 tem sentido somente a partir do segmento $\mathrm{S} 2$, a sequência $\mathrm{S} 1$ + S2 constitui um único enunciado (DUCROT, 1988, p. 53).

0 autor aplica essa regra novamente ao enunciado abaixo.

\section{Exemplo 3}

Faz calor lá fora, vamos passear (Hace calor afuera, vamos a pasear),

Essa aplicação é feita em um contexto em que o calor é uma razão suficiente para sair a passear, em que S1 = Faz calor lá fora e S2 = vamos passear. Nesse caso, S1 é um argumento para S2 e, consequentemente, constituem juntos um só enunciado. Segundo Ducrot (1988, p. 54), dada a função argumentativa do enunciado acima, o primeiro segmento não comporta, sozinho, uma informação completa, ou seja, a informação dada por S1 não é compreensível se não se conhece S2.

A propósito do texto, Ducrot o define como "um discurso que se supõe ser objeto de uma única escolha e cujo fim, por exemplo, já é previsto pelo autor no momento em que o redige" (1987, p. 166).

A língua, de acordo com a Teoria da Argumentação na Língua (TAL), fornece-nos diferentes palavras, estruturas e frases para que as utilizemos e que funcionam diferentemente, do ponto de vista argumentativo. Os estudos de Ducrot e seus colaboradores descrevem essas estratégias, entre as quais se encontram: 
a) Os operadores argumentativos - palavras como pouco, um pouco até, mas, logo, inclusive etc. que apontam a direção ou a forma argumentativa dos enunciados em que aparecem;

b) Os enunciados negativos, humorísticos e irônicos;

c) Estruturas linguístico-discursivas que assinalam a polifonia de locutores e de enunciadores - utilização de diferentes pontos de vistas ou vozes em um discurso;

d) A pressuposição - utilização de um conteúdo pressuposto (implícito linguístico) em um enunciado;

e) A argumentação por autoridade - utilização de um enunciado (ou ponto de vista) atribuído a uma autoridade, discursivamente constituída.

A esta lista acrescentamos os modalizadores discursivos, objeto de nossas investigações (NASCIMENTO, 2005; 2012c):

f) Modalizadores discursivos - elementos linguísticos que imprimem subjetividade no enunciado em que aparecem, direcionando a sua leitura: é certo que, é provável que, pode, deve, felizmente etc.

\section{A argumentação na leitura e na análise linguística}

As maiores dificuldades dos alunos, no processo de ensino-aprendizagem das estratégias argumentativas retóricas, podem ocorrer porque esses não conseguem diferenciar um assunto, um ponto de vista e um argumento favorável ou contrário a um determinado ponto de vista (NASCIMENTO, 2012a). Essa distinção é básica para qualquer trabalho com a argumentação e deve ser trabalhada desde as séries iniciais. 
Embora a argumentação esteja presente em todos os gêneros discursivos, em maior ou menor grau, alguns gêneros parecem ser mais propícios para desenvolver esta habilidade, do ponto de vista pedagógico. Entre esses, estão os chamados gêneros opinativos, em que as estratégias argumentativas são mais explícitas, em razão da própria função sociodiscursiva desses gêneros (emitir um posicionamento a respeito de um dado objeto): é o caso do artigo de opinião, do editorial e do debate, por exemplo. Por esta razão, mostraremos, a seguir, como trabalhar o uso das estratégias argumentativas retóricas e linguísticas, no artigo de opinião. Esse gênero é comumente descrito como aquele em que um locutor (jornalista ou não) desenvolve sua ideia a respeito de um determinado fato ou problema social e apresenta sua opinião. Geralmente, mas não sempre, o articulista é um especialista no assunto ou área de conhecimento de que trata o texto do artigo.

De acordo com Nascimento (2010), o artigo de opinião não tem a função de divulgar a opinião oficial da instituição jornalística, que caberia ao editorial. Por essa razão, ele é assinado, já que é de responsabilidade de quem o produziu. No entanto, assinala que "a direção de um jornal não escolhe seus articulistas aleatoriamente e, com certeza, prioriza aqueles que comungam das ideias, valores e interesses da empresa jornalística e do seu corpo editorial".

Melo (2003) afirma que duas características são indispensáveis no artigo de opinião: atualidade e opinião. Isso ocorre porque o leitor espera que o artigo trate de fatos contemporâneos ou ideias atuais e que o articulista emita um ponto de vista explícito sobre esses fatos ou ideias.

No que se refere à linguagem do gênero, Nascimento (2010) afirma que prevalece a impessoalidade ( $3^{\mathrm{a}}$ pessoa ou $1^{a}$ do plural), no entanto lembra que é possível encontrar ar- 
tigos na 1a pessoa do singular. Acrescenta que o texto se estrutura em torno de um ponto de vista com argumentos que o sustentam e que ainda pode apresentar uma conclusão com instruções ou orientação social. Por essa razão, é comumente descrito como um texto doutrinário, no sentido em que sugere ao leitor uma maneira de ver ou julgar um determinado fato social.

Em função desse caráter doutrinário, é importante que o professor de língua portuguesa, ao levar esse gênero para a sala de aula, esteja atento para identificar de que maneira, e com que recursos linguístico-discursivos, o articulista tenta levar o leitor a admitir determinada posição ou julgamento. (NASCIMENTO, 2010, p. 69).

Assim, o trabalho com esse gênero, no que se refere à leitura, passa, inicialmente, pela identificação do assunto que é abordado no texto, do ponto de vista defendido a respeito desse assunto, dos argumentos utilizados para a defesa desse ponto de vista e pela identificação da proposta de intervenção social (se houver). Em seguida, devem-se analisar as estratégias linguísticas que materializam o caminho argumentativo no gênero, tais como operadores argumentativos, adjetivos avaliativos, entre outros.

A atividade ${ }^{6} 01$ mostra como isso pode ser feito.

6 As atividades aqui apresentadas foram elaboradas exclusivamente para este trabalho, no entanto atividades semelhantes a essas já foram aplicadas em salas de aula de ensino superior, em cursos de Português Instrumental e de Leitura e Produção de Textos, em diferentes cursos de graduação nos quais lecionamos, na Universidade Federal da Paraíba, bem como em cursos de formação de professores de Língua Portuguesa nos quais participamos. Dada a natureza deste trabalho e por questões de espaço, não discutiremos aqui como se deram essas aplicações, no entanto os resultados dessas aplicações podem ser consultados em Nascimento (2015) e em Nascimento e Andrade (2014). 


\section{Atividade 01}

0 texto abaixo é um artigo de opinião, publicado pela Folha de São Paulo, em 07 de dezembro de 2012. Leia-o com atenção e responda às questões que seguem:

\section{Transparência já!}

No dia 13, a Câmara aprovou um projeto de lei que é uma revolução na relação entre Estado e sociedade.

0 texto obriga que o consumidor seja informado sobre o valor dos impostos federais, municipais e estaduais que incidem sobre mercadorias ou serviços adquiridos.

Dentre as muitas distorções do sistema tributário brasileiro (como alíquotas elevadas, superposição de tributos, complexidade, burocracia e regressividade), podemos acrescentar a falta de transparência, que impede que a população saiba quanto e como está pagando seus impostos.

Considerando a importância de o cidadão ter clara noção de que é um contribuinte --e tem o direito de exigir contrapartida do Estado pelos impostos que paga--, apresentei, quando deputado constituinte, proposta que se transformou no quinto parágrafo do artigo 150 da Constituição.

O texto: "A lei determinará medidas para que os consumidores sejam esclarecidos acerca dos impostos que incidam sobre mercadorias e serviços". Esperava que na reforma tributária fosse dada transparência à tributação, cumprindo o dispositivo constitucional.

Passados muitos anos, a reforma não ocorreu e todas as mudanças realizadas no sistema tributário só aumentaram a falta de transparência.

Em 2006, quando presidente da Federação das Associações Comerciais do Estado de São Paulo, lançamos o De Olho no Impos- 
to, para mobilizar a população e cobrar a regulamentação do texto constitucional.

O movimento coletou mais de 1,5 milhão de assinaturas. Elas foram entregues ao então presidente do Senado, Renan Calheiros, que assumiu a paternidade do texto, referendado pelos líderes partidários.

A tramitação do projeto na Câmara foi muito demorada em virtude de resistências do Fisco em expor a enorme magnitude da tributação dos bens e serviços. Essa barreira foi vencida somente agora, graças ao empenho de parlamentares como os deputados Guilherme Campos e Walter Ihoshi (ambos PSD-SP) e das pressões das associações comerciais e de outras entidades empresariais e de trabalhadores.

A sistemática prevista na lei não pretende criar burocracia adicional para o comércio, uma vez que o cálculo dos impostos será feito por estimativa e elaborado por órgãos especializados, como o Instituto Brasileiro de Planejamento Tributário. A informação virá automaticamente, quando da emissão dos documentos fiscais das transações.

O objetivo da medida é permitir ao consumidor saber o quanto paga de impostos e mostrar que sua posição de contribuinte lhe dá o direito à cidadania plena: o poder de cobrar serviços e o dever de fiscalizar como são aplicados os tributos. E levando-se em conta que se trata de uma matéria de relações de consumo e não tributária, seria de grande valia se o texto fosse regulamentado pelas áreas de defesa do consumidor.

A lei é um passo indispensável, mas cabe às entidades iniciarem campanha para esclarecer empresários e consumidores sobre a importância de implementar a transparência tributária e, principalmente, difundir à população a consciência de que ela contribui para a sustentação do Estado e que por isso tem o direito à contrapartida. O lema da campanha De Olho no Imposto deve ser 
resgatado: "Pago, logo exijo".

0 projeto de lei vem ao encontro da legalidade, pois regulamenta o que está na Constituição desde 1988. É totalmente democrático, pois foi gerado pela iniciativa popular, aprovado no Senado e na Câmara e leva transparência à população. Vamos torcer agora pela sanção da presidenta Dilma Rousseff.

GUILHERME AFIF DOMINGOS, 69, é vice-governador do Estado de São Paulo. Foi secretário do Emprego e Relações do Trabalho do Estado de São Paulo (gestão José Serra) e deputado constituinte

1) De que fato social trata o texto?

2) Qual é o ponto de vista defendido pelo autor a respeito da aprovação do projeto de lei a que se refere o texto?

3) Que argumentos são utilizados pelo autor para defender o referido projeto?

4) Nos trechos que seguem identificamos alguns elementos linguísticos que estabelecem relação entre argumentos e pontos de vistas apresentados no texto. Identifique que efeitos de sentido são estabelecidos a partir do uso desses elementos linguísticos.

a) A sistemática prevista na lei não pretende criar burocracia adicional para o comércio, uma vez que o cálculo dos impostos será feito por estimativa e elaborado por órgãos especializados, como o Instituto Brasileiro de Planejamento Tributário.

b) 0 projeto de lei vem ao encontro da legalidade, pois regulamenta o que está na Constituição desde 1988.

c) A lei é um passo indispensável, mas cabe às entidades iniciarem campanha para esclarecer empresários e consumidores sobre a 
importância de implementar a transparência tributária...

5) 0 posicionamento do articulista frente a determinados argumentos e fatos relatados é perceptível por meio de alguns advérbios, adjetivos e outras expressões avaliativas presentes no texto. Nos trechos abaixo, diga com que provável intenção o locutor usou cada uma das expressões sublinhadas.

a) (...) a Câmara aprovou um projeto de lei que é uma revolução na relação entre Estado e sociedade.

b) A tramitação do projeto na Câmara foi muito demorada em virtude de resistências do Fisco em expor a enorme magnitude da tributação dos bens e serviços.

c) Essa barreira foi vencida somente agora, graças ao empenho de parlamentares...

d) É totalmente democrático, pois foi gerado pela iniciativa popular...

e) A lei é um passo indispensável, mas cabe às entidades...

f) A informação virá automaticamente, quando da emissão dos documentos fiscais das transações.

6) Com que objetivo, nos parágrafos quarto e quinto, o autor do texto faz referência ao artigo 150 da Constituição Federal?

7) 0 autor retoma, no final do penúltimo parágrafo, o tema da campanha De olho no Imposto: "Penso, logo exijo". Analise esse tema e responda:

a) Esse tema é uma paráfrase de que pensamento filosófico?

b) De que maneira esse tema se relaciona com o pensamento original?

c) Com que prováveis intenções o autor do texto retoma essa campanha ao falar do projeto de lei aprovado pela Câmara? 
Essa atividade de leitura leva o aluno, inicialmente, a identificar o assunto do texto, o ponto de vista defendido e os argumentos utilizados para dar sustentação a esse ponto de vista. Para responder à questão 01, identificando que o texto trata da aprovação do projeto de lei que obriga a identificação de impostos cobrados nas mercadorias e serviços, uma estratégia bastante eficaz seria a observação das palavras chaves, as que mais se repetem no texto: estratégia de leitura chamada de skimming.

Outra estratégia bastante eficaz para a identificação do assunto é a leitura do título ou dos primeiros parágrafos. No texto acima, isso não será possível a partir da leitura do título, mas a partir dos dois primeiros parágrafos, que explicitam o fato social objeto de análise, no texto.

Para responder à segunda questão proposta, identificando o ponto de vista do autor do artigo a respeito da aprovação do referido projeto de lei a que se refere o texto, é necessário ir mais além na leitura. 0 locutor defende que a lei é um passo indispensável, mas não o único, uma vez que cabe à sociedade exigir a transparência tributária. Esse posicionamento só aparece no penúltimo parágrafo, correlacionados pelo operador argumentativo mas, de contraposição. É esse elemento linguístico que vai demarcar o ponto de vista presente no texto.

É interessante observar que o ponto de vista defendido pelo locutor do texto não está presente nos primeiros parágrafos, mas é assinalado no título do texto. 0 título, por sua vez, adquire um sinal de protesto, com a utilização do advérbio já seguido de sinal de exclamação, após o substantivo transparência. Trata-se de uma estrutura linguística conhecida popularmente por palavra de ordem e comumente utilizada em mobilizações sociais.

Convém aqui observar que o locutor assinalou o seu 
ponto de vista, mas não o explicitou. Assim, optou por apresentar inicialmente os argumentos para depois apresentar o posicionamento explícito a respeito do assunto que está tratando. Os argumentos (resposta da questão 03) podem ser esquematizados da seguinte maneira:

1) A falta de transparência é uma das distorções do sistema burocrático brasileiro;

2) Experiência do articulista com o assunto - como constituinte;

3) Referência à Constituição Federal;

4) Lançamento da proposta da lei em 2006;

5) Campanha De olho no imposto - mobilização para discutir a transparência na cobrança de tributos e encaminhar a proposta;

6) Relato na tramitação da lei - resistências do Fisco;

7) A finalidade da lei é desburocratizar;

8) A lei vem ao encontro da legalidade.

Além disso, pode ser solicitado ao aluno que identifique os tipos de argumentos utilizados: se são fatos (argumentos 4, 5 e 6), presunções (1 e 8), objetivos (7), citações (3), depoimentos (2), exemplos etc.

É importante levar o aluno a perceber o movimento argumentativo realizado pela presença dos diferentes argumentos no texto, que finaliza com o ponto de vista explicitamente posto no penúltimo parágrafo. Para contribuir na percepção dessa relação, a questão 04 solicita que o aluno identifique relações de sentido entre argumentos e pontos de vista apresentados no texto: causa/efeito na letra a, explicação ou justificativa na letra b, contraposição na letra c.

Na verdade, a quarta questão pede que o aluno verifique os efeitos de sentido que os operadores argumentativos (conjunções) geram no texto. É importante observar que não se so- 
licitou classificação, mas que o aluno analise o funcionamento discursivo e argumentativo de cada um desses elementos.

Verificando como os operadores funcionam discursivamente, os alunos vão, aos poucos, identificando os argumentos e observando como esses são postos em um texto. Assim, o professor sai da mera classificação desses elementos de coesão textual, para seu uso linguístico efetivo. Na atividade 02, mais adiante, discutiremos um pouco mais a esse respeito.

A questão de número 05, por sua vez, tem o objetivo de fazer o aluno refletir sobre o uso de determinadas expressões de caráter avaliativo, denominadas de modalizadores discursivos, que aparecem no artigo de opinião e que contribuem para a identificação de pontos de vista, posicionamentos e análises realizadas pelo autor do texto, com relação às informações e argumentos apresentados no texto.

Conforme se observa nos trechos propostos para análise, essas expressões modalizadoras são compostas por diferentes estruturas linguísticas: adjetivos (letra e), advérbios (letra f), grupos nominais com valor adjetivo (letras a, b e d), expressões adverbiais (letra c) etc. No entanto, chamamos a atenção para o fato de que não foi solicitada a identificação dessas estruturas, o que nada contribuiria para a compreensão do texto, muito menos para compreender os movimentos argumentativos. 0 que se pede é que o aluno seja capaz de verificar com que possíveis intenções argumentativas essas expressões foram utilizadas no texto. Ao realizar isso, o aprendiz não só identifica o significado dessas expressões, mas o seu uso, produzindo os mais diferentes efeitos argumentativos.

Por fim, as questões 06 e 07 trabalham com a questão da polifonia ou da intertextualidade. Essas questões solicitam que o aluno identifique vozes e textos de outros locutores trazidos pelo articulista, com o objetivo de fundamentar seus 
posicionamentos. No entanto, conforme se observa nos enunciados dessas questões, não basta reconhecer essas vozes, é preciso observar com que intenções o autor do texto as utiliza.

Considerando que o artigo é um gênero através do qual se emite opinião a respeito de fatos e ideias presentes na sociedade, é de se esperar que ocorra a referência a outros textos. É por essa razão que uma das características argumentativas desse gênero é a polifonia. Reiteramos que não basta identificar marcas polifônicas (vozes, depoimentos e citações) presentes no artigo. É imprescindível verificar de que maneira essas marcas são utilizadas argumentativamente, ou seja, com que intenção o articulista as recupera, no seu texto.

Como se vê acima, as estratégias argumentativas retóricas funcionam conjuntamente com as linguísticas, no gênero, no sentido de contribuir para a explicitação do ponto de vista do responsável pelo texto e para a materialização das suas possíveis intenções. Por essa razão, devem ser trabalhadas conjuntamente, no processo de leitura e de escrita, não só do gênero artigo de opinião, mas de vários outros.

Além de serem trabalhadas no processo de leitura e, consequentemente, na produção textual ${ }^{7}$, algumas dessas estratégias podem ser abordadas no processo de análise linguística, com as mais diferentes estruturas (classes de palavras, funções sintáticas, léxico etc.) da língua. Para se compreender melhor como isso pode ser feito, apresentamos, a seguir, atividades de análise linguística que contemplam o funcionamento de operadores argumentativos (conjunções), ilustrando como trabalhar

7 Em razão dos nossos objetivos, não discutimos, neste trabalho, o ensino da argumentação na produção textual. No entanto, o ensino da produção oral e escrita não pode prescindir do trabalho com a argumentatividade, conforme já mencionamos em trabalhos anteriores (NASCIMENTO, 2012a; 2012b). Em Nascimento e Andrade (2014, e em Nascimento (2014), é possível verificar como é possível trabalhar com as estratégias argumentativas retóricas e linguísticas, durante o processo de ensino-aprendizagem de produção textual. 
com a argumentação em um tópico gramatical específico.

\section{Atividade 02}

1. Complete o enunciado abaixo com o segmento SER APROVADO, fazendo as adequações necessárias, a partir das palavras sublinhadas.

Carlos estudou e

Carlos estudou mas

Carlos estudou porque

Carlos estudou logo

2. Que efeito de sentido gerou cada palavra sublinhada na questão anterior?

3. Agora substitua a palavra sublinhada por outras que mantenham o mesmo efeito de sentido (de contraposição) no enunciado que segue:

Pedro estudou muito, mas fez uma péssima prova.

4. A partir do enunciado da questão anterior (Pedro estudou muito, mas fez péssima prova), se pode concluir que:

Pedro será aprovado

Pedro será reprovado

Pedro não gosta de estudar

Na atividade 02 , é proposto que o aluno reflita sobre o uso dos operadores, treine as habilidades de correlacionar argumentos a partir de operadores que geram efeitos distintos, bem como a partir de operadores que geram o mesmo efeito de sentido. Por fim, ainda se propõe que o aluno estabeleça 
conclusões a partir do uso de um determinado operador, em um enunciado.

Ao responder às questões 01 e 02 , da atividade, o aluno irá perceber que cada enunciado terá as continuações distintas e que os efeitos de sentido gerados também são distintos:

a) será provado (relação de soma de argumentos - estudar e aprovar se somam);

b) não será aprovado (contraposição de argumentos que levam a conclusões contrárias - estudar não significa aprovar, necessariamente);

c) quer ser aprovado (relação entre causa e consequência, apresentando objetivo ou finalidade - estudar para aprovar);

d) será aprovado (relação entre argumento e conclusão - o estudo leva à aprovação).

Essas duas primeiras questões têm a finalidade de levar o aluno a refletir que os mesmos argumentos correlacionados por operadores distintos estabelecem relações de significação e argumentação distintas. Assim, a argumentação não está apenas nos argumentos utilizados, mas, principalmente, nos operadores utilizados para correlacioná-los.

Na questão 03, o aluno é convidado a reescrever o mesmo enunciado com outros operadores cuja troca não interfira no seu sentido. Isso é possível se o aluno utilizar operadores de contraposição: "porém", "no entanto", "entretanto", "embora" etc. 0 objetivo da tarefa é fazer o aluno refletir que um determinado efeito de sentido pode ser gerado por diferentes operadores, em outras palavras, a meta é fazer o aluno perceber que toda vez que quiser contrapor argumentos que levam a conclusões contrárias, ele poderá escolher diferentes elementos da língua para realizar essa mesma função: não terá de usar sempre a palavra "mas". A questão 04 contribui para o aluno perceber a conclusão pretendida pelo locutor ao 
utilizar o operador "mas" (e seus equivalentes no enunciado): qual seja levar a conclusão de que Pedro será reprovado.

Os operadores argumentativos ainda podem ser trabalhados de outras maneiras: é possível, inclusive, retirar-se os operadores do texto e pedir que os alunos preencham os espaços com operadores. Em seguida, discutem-se e se contrastam as respostas dos alunos com o texto original. Esse tipo de atividade faz o aluno perceber que um mesmo efeito de sentido se consegue com diferentes operadores da língua.

A argumentatividade, em alguns gêneros, pode se manifestar por meio de de estratégias polifônicas, da presença de modalizadores e de conteúdos pressupostos. A tirinha (ou tira cômica), um dos gêneros do universo jornalístico, por exemplo, é muito propícia para o aparecimento de elementos modalizadores funcionando com estratégia argumentativa. A atividade que segue explora estratégias argumentativas modalizadoras necessárias para a compreensão textual.

\section{Atividade 03}

Considere o texto abaixo e faça o que se pede.
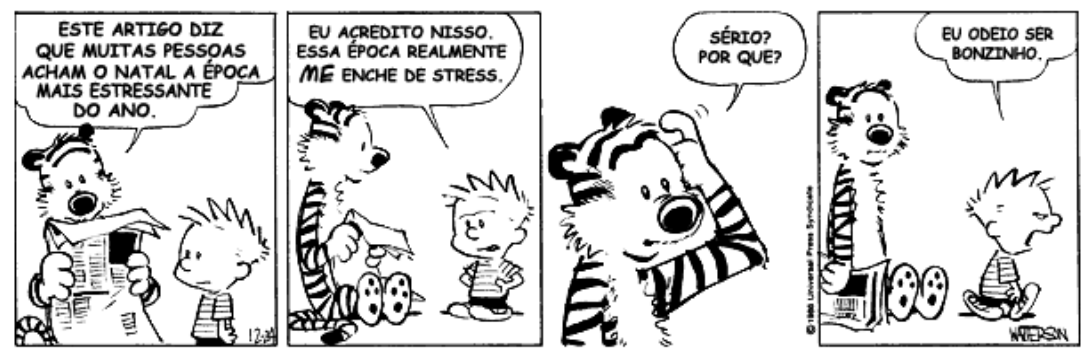

〈http://depositodocalvin.blogspot.com/2008/04/calvin-haroldo-tirinha-401.html 
1. Assinale a alternativa verdadeira: No segundo quadrinho ao afirmar "Eu acredito nisso", Calvin expressa:

( ) uma certeza de que o Natal é a época mais estressante do ano;

( ) uma possibilidade de o Natal ser a época mais estressante do ano;

( ) uma dúvida quanto a afirmação de o Natal ser estressante;

( ) um ponto de vista ou julgamento pessoal, considerando o Natal como algo ruim.

2. No terceiro quadro, a expressão facial de Haroldo e o seu questionamento (Sério? Por quê?) indicam que:

( ) Ele não está surpreso com o que Calvin lhe falou.

( ) Ele acredita também no que Calvin lhe falou.

( ) Ele não concorda com Calvin.

( ) Ele expressa curiosidade a respeito do que Calvin lhe falou.

3. Em "Eu odeio ser bonzinho", o sufixo -inho funciona como um elemento avaliativo. Diga que avaliação é expressa por esse elemento e, a partir dessa avaliação, apresente a crítica formulada pelo chargista com relação ao comportamento das pessoas, no Natal.

0 texto da atividade 03 ilustra como elementos modalizadores ("Eu acredito", “o sufixo -inho", "sério?") podem funcionar argumentativamente, imprimindo efeitos e posicionamentos. É exatamente isso que a atividade propõe: que o aluno leia esses elementos e veja que eles contribuem para um ponto de vista que está sendo veiculado, uma crítica a respeito do Natal. Na primeira questão, é solicitado ao aluno que observe 
o funcionamento da expressão "Eu acredito". Essa foi utilizada para emitir a certeza do personagem Calvin relativa ao conteúdo do enunciado: o Natal é a época mais estressante do ano. Ponto de vista esse que causa surpresa e curiosidade no outro personagem presente na tira, surpreendido com o posicionamento de Calvin. A questão 02 explora exatamente esse posicionamento da personagem presente na sua expressão facial e nas palavras utilizadas: "Sério?" "Por quê?".

Por fim, a última questão chama a atenção para a modalização presente no avaliativo "bonzinho", expressa pelo sufixo -inho. Mediante essa modalização, uma avaliação irônica de Calvin a respeito da ideia de ser bom, no Natal, estão veiculados o posicionamento e a crítica presentes na tira. Para Calvin, é estressante o Natal, porque o garoto tem de ser bom, como se espera que todas as pessoas sejam nessa época do ano. Na verdade, grande parte delas apenas o finge, é isso o que o autor ironiza por meio do sufixo modalizador avaliativo -inho, que expressa uma avaliação de natureza irônica.

Os modalizadores são elementos bastante eficazes, do ponto de vista argumentativo, porque se prestam, exatamente, para veicular sentidos. Além disso, funcionam como marcas daquilo que o locutor responsável pelo texto pretende, com relação a seu interlocutor. Eles podem, inclusive, ser isolados e trabalhados em comparação, para que o aluno perceba o funcionamento desses elementos, como já assinalamos em outros trabalhos.

Trabalhar a modalização na análise linguística é criar condições para que o aluno tome consciência do uso dos modalizadores discursivos, em diferentes enunciados. Isso pode ser feito através de diferentes atividades através das quais o aluno possa comparar enunciados em que aparecem elementos modalizadores (NASCIMENTO, 2012b, p. 09). 
Para o trabalho com os modalizadores, propomos a realização de três tipos de atividades de análise linguística: a) 0 primeiro tipo consiste em apresentar um mesmo enunciado variando o modalizador, para que o aluno possa verificar as diferenças de sentido geradas por esse recurso no enunciado; b) 0 segundo é exatamente o inverso do anterior, ou seja, propõem-se enunciados distintos em que ocorra o mesmo modalizador, a fim de que os alunos identifiquem os efeitos de sentido que esse elemento gera em cada enunciado; e c) 0 terceiro tipo, por sua vez, consiste em fornecer aos alunos um enunciado e pedir que eles acrescentem ao conteúdo desse enunciado uma determinada avaliação, para qual terão de se valer de diferentes elementos modalizadores que expressem essa avaliação específica.

Atividades semelhantes às que propusemos neste artigo podem ser realizadas, em sala de aula, no sentido de trabalhar com o funcionamento argumentativo de outros elementos e estruturas da língua. Isso é possível por meio da análise e da comparação das diferentes estruturas linguísticas voltando-se para o seu uso, em diferentes gêneros textuais e contextos linguístico-discursivos.

Ainda no que se refere ao ensino das estratégias argumentativas, convém assinalar que as atividades de leitura e de análise linguística em que aparecem os elementos linguístico-discursivos que imprimem argumentatividade no texto devem ser pensadas levando em consideração o repertório e o nível linguístico dos alunos. Atividades mais complexas, em grupos mais elementares, não só dificultam o trabalho como promovem o risco de fracassos desnecessários.

O ideal é que ocorra uma gradação, partindo sempre dos elementos argumentativos do uso mais ordinário, sobretudo aqueles retóricos e linguísticos que aparecem em gêneros textuais que os alunos já dominam, para aqueles que aparecem 
em contextos mais complexos de uso da língua e em gêneros mais complexos.

\section{Considerações Finais}

Propusemo-nos, neste trabalho, discutir a argumentatividade em alguns gêneros do universo jornalístico e no processo da análise linguística, fazendo uma correlação com o ensino de língua materna. Inicialmente, apresentamos os princípios teóricos da argumentação na retórica e na língua.

0 estudo teórico acabou por nos levar a refletir sobre a importância do trabalho com a argumentação, no ensino de língua materna, como uma habilidade necessária para formar leitores e produtores textuais competentes. Propusemos, por conseguinte, que o ensino de argumentação não seja dissociado do processo de ensino-aprendizagem da leitura, da análise linguística (e consequentemente da produção textual), já que a argumentação está inscrita na própria língua (como afirma Ducrot) e, por sua vez, no discurso (Nascimento 2005), sendo presente, em maior ou menor grau, em todos os gêneros (Nascimento 2012a, 2012c).

Por fim, ainda apresentamos sugestões de atividades para trabalhar a argumentatividade no processo de leitura e de análise linguística, considerando a necessidade de compreender esse fenômeno como algo inerente à interação humana e à linguagem.

Para finalizar, gostaríamos de sugerir que o trabalho com a argumentação requer que o professor pense nesse fenômeno de uma forma mais ampla: não apenas como uma simples habilidade para convencer alguém a respeito de algo. A argumentação está presente em todas as interações que realizamos e se materializa nas expressões linguísticas, nos sons, imagens, 
gestos e outros signos que produzimos, quando interagimos.

Para ler e produzir textos, de maneira eficiente, utilizamos diferentes estratégias argumentativas (retóricas e linguísticas), que devem ser adequadas ao contexto em que estamos inseridos e ao gênero mobilizados, a fim de atingir os objetivos interacionais a que nos propusermos. Dessa maneira, o trabalho com a leitura, com a análise linguística e com a produção de textos, na sala de aula, não pode prescindir do trabalho com a argumentação.

\section{REFERÊNCIAS}

ANSCOMBRE, J. C.; DUCROT, O. La argumentación en la lengua. Versión española de Julia Sevilla e Marta Tordesillas. Madrid: Editorial Gredos S.A., 1994.

ARISTÓTElES. Arte Retórica e Arte Poética. 16. ed. Rio de Janeiro: Ediouro, s.d.

BAKHTIN, M. Estética da criação verbal. Tradução Paulo Bezerra. 3. ed. São Paulo: Martins Fontes, 2000.

DUCROT, O. 0 dizer e o dito. Revisão técnica da tradução Eduardo Guimarães. Campinas, SP: Pontes, 1987.

DUCROT, O. Polifonia y Argumentación: Conferencias del Seminario Teoría de la Argumentación y Análisis del Discurso. Cali: Universidad del Valle, 1988.

ESPÍNDOLA, L. O Gênero Discursivo Charge: Leitura e Ensino. 2003. Trabalho apresentado no V Encontro sobre 
Mídia, Educação e Leitura no IV COLE - Congresso de Leitura do Brasil. Campinas-SP: ALB/UNICAMP, 22 a 25 de julho de 2003. (Mimeografado)

MELO, J. M. A Opinião no Jornalismo Brasileiro. 3. ed. Campos do Jordão: Mantiqueira, 2003.

HYMES, D. H. Acerca de la competencia comunicativa. In: LLOBERA, M. et al. Competencia comunicativa: documentos básicos en la enseñanza de lenguas estranjeras. Madrid: Edesla Grupo Didascalia, 2000.

PERELMAN, C. O Império Retórico: Retórica e Argumentação. 2. ed. Lisboa: Asa Editores, 1999.

NASCIMENTO, E. P. A modalização e o ensino de leitura e escrita dos gêneros formulaicos. In: FERRAZ, M. M. T.; NASCIMENTO, E. P. (Org.). Semântica e Ensino. Curitiba: Editora CRV, 2015.

NASCIMENTO, E. P. A modalização e o ensino de leitura e de escrita dos gêneros formulaicos. In: FERRAZ, M. M. T.; NASCIMENTO, E. Semântica e Ensino. Curitiba: Editora CRV, 2015.

NASCIMENTO, E. P. Gêneros textuais, argumentação e ensino. In: PEREIRA, R. C. M. (Org.). A didatização de gêneros no contexto da formação continuada. João Pessoa: Editora Universitária da UFPB, 2012a.

NASCIMENTO, E. P. A modalização no ensino de língua: contribuições para o processo de leitura, análise linguística e produção textual. In: ANAIS da Jornada Nacional de Estudos 
Linguísticos do Nordeste. Natal: EDUFRN, 2012b. p. 1-12. Disponível em: 〈http://www.gelne.org.br/Site/〉. Acesso em: 15 dez. 2015.

NASCIMENTO, E. P. Apresentação. In: NASCIMENTO, E. P. A argumentação na redação comercial e oficial: estratégias semântico-discursivas em gêneros formulaicos. João Pessoa: Editora Universitária da UFPB 2012c.

NASCIMENTO, E. P. Gêneros jornalísticos na sala de aula: desenvolvendo habilidades leitoras. In: PEREIRA, R. C. M. (Org.). Ações de linguagem: da formação continuada à sala de aula. João Pessoa: Editora Universitária da UFPB, 2010.

NASCIMENTO, E. P.; ANDRADE, L. H. S. A sequência didática para o ensino de produção textual em línguas materna e estrangeira: uma experiência no contexto universitário. In: LINS, J. N.; ROCHA, C. R. R. (Org.). Diálogos Interdisciplinares: linguística, literatura e ensino. Recife: Editora UFPE, 2014.

NASCIMENTO, E. P. Jogando com as vozes do outro: argumentação na notícia jornalística. 2005. Tese (Doutorado em Letras). Universidade Federal da Paraíba/PPGL, João Pessoa, 2005.

Artigo recebido em junho de 2015 e aprovado em setembro de 2015.

Disponível em: http://seer.fclar.unesp.br/casa 